\title{
COMMON FIXED POINT THEOREMS FOR GENERALIZED NON-EXPANSIVE SEMI-TOPOLOGICAL SEMIGROUPS IN LOCALLY CONVEX SPACES
}

\author{
TAMER NABIL ${ }^{1,2}$ AND AHMED H. SOLIMAN ${ }^{1,3}$
}

${ }^{1}$ King Khalid University, Faculty of Science, Mathematics Department, Abha 9004, Saudi Arabia ${ }^{2}$ Suez Canal University, Faculty of Computers and Informatics

Department of Basic Science, Ismailia, Egypt

E-mail: $t_{-}$3bdelsadek@yahoo.com

${ }^{3}$ Department of Mathematics, Faculty of Science, Al-Azhar University Assiut Branch, Assiut 71524, Egypt

E-mail: ahsolimanm@gmail.com

\begin{abstract}
In this paper, we shall be concerned with a special kind of equicontinuous semi-topological semigroups of self-mappings on a weakly compact convex subset of a separated locally convex space, namely, the generalized non-expansive mappings and we shall introduce some common fixed point results for this kind of semigroups. Also, we study a characterization of the existence of a left invariant mean on almost and weakly almost periodic functions on separable semi-topological semigroups. Our results extend the results due to Lau and Zhang [17] and Lau [13].

Key Words and Phrases: Fixed point property, non-expansive mapping, generalized nonexpansive mapping, weakly compact convex set, weakly almost periodic, reversible semigroup, invariant mean.
\end{abstract}

2010 Mathematics Subject Classification: 47H10, 47H20, $43 \mathrm{~A} 07$.

Acknowledgments. The authors extend their appreciation to the Deanship of Scientific Research at King Khalid University for funding this work through General Research Project under grant number ( G.R.P- 009-38 ). Also, the authors thank Prof. Dr. Anthony To-Ming Lau (University of Alberta, Edmonton, Alberta, Canada) with whom I had fruitful discussions and useful comments regarding this work. And, special thanks are due to the referees for their deep insight.

\section{REFERENCES}

[1] A. Abkar, M. Eslamian, Fixed point theorems for Suzuki generalized nonexpansive multivalued mappings in Banach spaces, Fixed Point Theory Appl., 2010(2010), Article ID 457935.

[2] T.D. Benavides, M.A.J. Pineda, Fixed points of nonexpansive mappings in spaces of continuous functions, Proc. Amer. Math. Soc., 133(2005), 3037-3046.

[3] T.D. Benavides, M.A.J. Pineda, S. Prus, Weak compactness and fixed point property for affine mappings, J. Funct. Anal., 209(2004), 1-15.

[4] F.E. Browder, Non-expansive nonlinear operators in Banach spaces, Proc. Natl. Acad. Sci. USA, 54(1965), 1041-1044. 
[5] A.H. Clifford, G.B. Preston, The Algebraic Theory of Semigroups, Vol. 1, Math. Surveys, no. 7, Amer. Math. Soc., Providence, R.I., 1961.

[6] M.M. Day, Amenahle semigroups, Illinois J. Math., 1(1957), 509-544.

[7] R.E. De Marr, Common fixed points for commuting contraction mappings, Pacific J. Math., 13(1963), 1139-1141

[8] P.N. Dowling, C.J. Lennard, B. Turett, Weak compactness is equivalent to the fixed point property in c0, Proc. Amer. Math. Soc., 132(2004), 1659-1666.

[9] K. Goebel, W.A. Kirk, Topics in Metric Fixed Point Theory, Cambridge Stud. Adv. Math., vol. 28, Cambridge Univ. Press, Cambridge, 1990.

[10] K. Goebel, W.A. Kirk, Classical theory of nonexpansive mappings, in: Handbook of Metric Fixed Point Theory, Kluwer Acad. Publ., Dordrecht, 2001, 49-91.

[11] R.D. Holmes, A. Lau, Nonexpansive actions of topological semigroups and fixed points, J. London Math. Soc., 5(1972), 330-336.

[12] W.A. Kirk, A fixed point theorem for mappings which do not increase distances, Amer. Math. Monthly, 72(1965), 1004-1006.

[13] A.T.-M. Lau, Invariant means on almost periodic functions and fixed point properties, Rocky Mountain J. Math., 3(1973), 69-76.

[14] A.T.-M. Lau, Some fixed point theorems and $W^{*}$-algebras, Fixed Point Theory and Applications (S. Swaminathan-Ed.), Academic Press, (1976), 121-129.

[15] A.T.-M. Lau, Amenability of semigroups, The analytic and topological theory of semigroups (K.H. Hoffmann, J.D. Lawson, J.S. Pym-Eds.), W. de Gruyter, Berlin, 1990, 313-334.

[16] A.T.-M. Lau, Amenability and fixed point property for semigroup of nonexpansive mappings, Fixed Point Theory and Applications (in: M.A. Thera, J.B. Baillon), Pitman Research Notes Mathematical Series, 252(1991), 303-313.

[17] A.T.-M. Lau, Y. Zhang, Fixed point properties of semigroups of non-expansive mappings, J. Funct. Anal., 254(2008), 2534-2554.

[18] A.T.-M. Lau, Y. Zhang, Fixed point properties for semigroups of nonlinear mappings and amenability, J. Funct. Anal., 263(2012), no. 10, 2949 - 2977.

[19] T. Mitchell, Fixed points of reversible semigroups of nonexpansive mappings, Ködai Math. Sem. Rep., 22(1970), 322-323.

[20] D.R. Sahu, D. O'Regan, R.P. Agarwal, Fixed Point Theory for Lipschitzian-Type Mappings with Applications, Springer-Verlag, Berlin, 2009.

[21] A.H. Soliman, A coupled fixed point theorem for nonexpansive one parameter semigroup, J. Adv. Math. Stud., 7 (2014), no. 2, 28-37.

[22] T. Suzuki, Fixed point theorems and convergence theorems for some generalized nonexpansive mappings, J. Math. Anal. Appl., 340(2008), 1088-1095.

[23] W. Takahashi, Fixed point theorem for amenable semigroups of nonexpansive mappings, Kodai Math. Sem. Rep., 21(1969), 383-386.

Received: November 5, 2014; Accepted: May 14, 2015. 